\title{
CORRIGENDUM
}

\section{APTITUDE AS GRAMMATICAL SENSITIVITY AND THE INITIAL STAGES OF LEARNING JAPANESE AS A L2: PARAMETRIC VARIATION AND CASE MARKING-CORRIGENDUM}

\section{Bill VanPatten and Megan Smith}

Michigan State University

doi:10.1017/S0272263114000345, Published by Cambridge University Press, 28 July 2014.

After the online publication of our article, we discovered that five participants were inadvertently placed into the subgroup of no resetting when in actuality they appear to possess a mixed pattern of reading times. We thus would like to emend our article with the following information; this addition would be in the first paragraph of the Results section before the last sentence.

Five participants within the no resetting group actually demonstrated mixed results. First, they patterned like the other groups in that they had longer mean reading times on the ungrammatical SVO sentences compared to the grammatical SOV sentences as well as longer mean reading times on correctly case-marked sentences compared to anomalous casemarked sentences. However, on the $k a$ sentences, they patterned like the no resetting group, whereas on the toh sentences, they patterned like the complete group. Yet, their reading times on the toh sentences did not yield a significant difference: $t(4)=-2.14, p=.10$. Because these reading time differences were not significant, we have left these five participants in the no resetting group. 
This correction does not change our overall results, discussion, or conclusion in any way. Since the online publication of our article, we reanalyzed the data by removing these five participants. We obtained the same statistical outcomes as in the published version, albeit with slightly different means for the overall reading times and slight adjustments to the $F, t, p$, and $\eta$ values in our statistics. Again, all significant and nonsignificant differences from our original analyses held. The authors apologize for any confusion this corrigendum causes.

\section{REFERENCE}

VanPatten, B., \& Smith, M. (2014). Aptitude as grammatical sensitivity and the initial stages of learning japanese as a L2: Parametric variation and case marking. Studies in Second Language Acquisition, doi:10.1017/S0272263114000345. 